\title{
Calcification of modern foldable hydrogel intraocular lens designs
}

\begin{abstract}
Purpose To report and compare clinical and pathological features of hydrophilic acrylic intraocular lenses (IOLs) of three major designs, explanted from patients who had visual disturbances caused by opacification of the lens optic.
\end{abstract}

Methods Eighty-seven hydrophilic acrylic IOLs (25 Hydroview ${ }^{\mathrm{TM}}$, 54 SC60B-OUV, and 8 Aqua-Sense $^{\mathrm{TM}}$ lenses) were explanted and sent to our center. Most patients became symptomatic during the second year after cataract surgery. A fine granularity was observed on the surface of the lens optic in the case of Hydroview ${ }^{\mathrm{TM}}$. With the SC60B-OUV and Aqua-Sense ${ }^{\mathrm{TM}}$ lenses, the opacity resembled a nuclear cataract. Gross examination, light microscopy and staining with alizarin red and the von Kossa method (for calcium) were performed. Some lenses were submitted for scanning electron microscopy (SEM) and energy-dispersive $\mathrm{X}$-ray spectroscopy (EDS).

Results Light microscopic and SEM analyses revealed the presence of irregular granular deposits on the external optical surfaces of Hydroview $^{\mathrm{TM}}$ lenses. With the SC60B-OUV lenses, the opacity was caused by the presence of multiple fine, granular deposits within the lens optic, distributed in a line parallel to the anterior and posterior curvatures of the optic, with a clear zone just beneath its external surfaces. The Aqua-Sense ${ }^{\mathrm{TM}}$ lenses exhibited both patterns simultaneously. The deposits in all cases stained positive with alizarin red and von Kossa method. EDS also demonstrated the presence of calcium and phosphates within the deposits.

Conclusion Differences in the water content of the hydrophilic acrylic materials used in the manufacture of these three lens designs may be responsible for the different patterns of calcium precipitation. Careful clinical follow up of patients implanted with these lenses is
AM Izak, L Werner, SK Pandey and DJ Apple

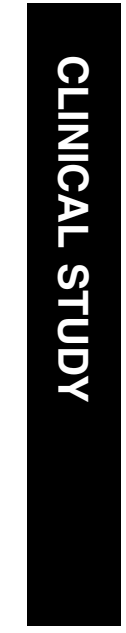

Keywords: intraocular lens; cataract surgery; calcification, hydrogel; surface analysis

\section{Introduction}

Foldable hydrophilic acrylic intraocular lenses (IOLs), also popularly known as hydrogel lenses, are not yet available in the United States but have been marketed by several firms for several years in international markets. Most of the currently available hydrophilic acrylic lenses are manufactured from different acrylic copolymers with water contents ranging from 18 to $28 \%$, and an incorporated UV absorber. ${ }^{1,2}$ They are packaged in a vial containing distilled water or balanced salt solutions, thus being already implanted in the hydrated state and in their final dimensions. Hydration renders these lenses flexible, enabling the surgeons to fold and insert/inject them through small incisions. Many surgeons have adopted the use of hydrophilic acrylic IOLs because of their easier handling properties and biocompatibility., Although hydrophilic surfaces have been shown to lower the inflammatory cytological response to the $\mathrm{IOL}^{4}$, some currently available hydrophilic acrylic IOL designs have been associated with reports on late postoperative opacification caused by calcium precipitation. ${ }^{5-30}$ We describe here the analyses performed in our laboratory on hydrophilic acrylic lenses of three major designs during the past 3 years. They were all explanted because of whitish discoloration of the optic component, or of the whole lens, related to different forms and degrees of dystrophic calcification (L Werner, DJ Apple, SK Pandey. Late postoperative opacification of hydrophilic intraocular lens designs, presented at the ASCRS Symposium on
Center for Research on Ocular Therapeutics and Biodevices

Storm Eye Institute Medical University of South Carolina

Charleston, SC, USA

Correspondence:

L Werner

Storm Eye Institute

Department of

Ophthalmology

Medical University of South Carolina

167 Ashley Avenue

PO Box 250676

Charleston

SC 29425-5536

USA

Tel: + 18437920777

Fax: + 18437927920

E-mail: werner|@ musc.edu

Received: 26 February 2002 Accepted in revised form: 8 March 2002 
Cataract, IOL and Refractive Surgery, Best Paper of the Session, San Diego, CA, 28 April 2001; L Werner, DJ Apple, SK Pandey, AM Izak et al. Ground glass opalescence of hydrophilic acrylic intraocular lenses, poster presented at the Annual Meeting of the American Academy of Ophthalmology, New Orleans, LA, 11-14 November 2001; Pandey SK, Werner L, Apple DJ, Kaskaloglu M, Izak AM, Cionni RJ. Intraocular lens opacification, opacification, opacification, prize winning video, presented at the ASCRS Symposium on Cataract, IOL, and Refractive Surgery, Philadephia, PA, June 2002).

\section{Hydroview $^{\mathrm{TM}}$ (H60M)}

The first group of explanted hydrophilic acrylic lenses analysed in our center because of whitish discoloration was represented by the Bausch and Lomb Surgical (Rochester, NY, USA) Hydroview ${ }^{\mathrm{TM}}$ IOL. $^{8-13}$ The optic material of these IOLs is composed of a cross-linked copolymer of 2-hydroxyethyl methacrylate and 6hydroxyhexyl methacrylate, with a bonded benzotriazole-type UV absorber. The water content of this material is $18 \%$ and the refractive index is 1.474 . The haptics are modified $\mathrm{C}$ loops made of blue-colored PMMA, polymerically cross-linked with the optics by means of an interpenetrating polymer network, which provides a one-piece design with a true optic zone of $6.0 \mathrm{~mm}$. This IOL design has been implanted for several years in international markets; over 400000 have been implanted worldwide. However, although it was cleared for marketing in November 1999 by the United States Food and Drug Administration (FDA), it has not yet been launched for general implantation in this country.

Starting in November 1999, we have received in our center 25 explanted Hydroview ${ }^{\mathrm{TM}}$ lenses (Table 1) for pathological analyses. ${ }^{8-13}$ In each case, the lens has been explanted because of the presence of a granularity on its optical surfaces associated with decrease in visual acuity and glare, in the late postoperative period. At the time of explantation, the age of the 25 patients ranged from 54 to 92 years $(75.65 \pm 8.57)$. Two patients were in treatment for cardiovascular diseases, four were diabetic, and the others were otherwise healthy. The lenses were explanted from 4 to 40 months postoperatively $(24.42 \pm 10.18)$ after the primary procedure because of opacification observed at the level of the optics, associated with decrease in visual acuity (from $20 / 20$ after the primary procedure to hand movements in some cases) and significant glare. In only two cases, the lens was explanted earlier than 1 year after the primary procedure (4 and 10 months). The surgeons described the findings as a 'brown granularity' or 'small red corpuscles' present on both external optical surfaces of the lenses (Figure 1a). In some cases, the optic
Table 1 Hydrophilic acrylic IOLs of three major designs explanted in different countries because of postoperative calcification and analysed at the Center for Research on Ocular Therapeutics and Biodevices

\begin{tabular}{|c|c|c|c|}
\hline $\begin{array}{l}\text { IOL design/ } \\
\text { manufacturer }\end{array}$ & Physician & Country & $\begin{array}{l}\text { No. of } \\
\text { explants }\end{array}$ \\
\hline & A Apel & Australia & 1 \\
\hline & M Batterbury & UK & 1 \\
\hline & B Crayford & Australia & 1 \\
\hline \multirow{12}{*}{$\begin{array}{l}\text { Hydroview }(\mathrm{H} 60 \mathrm{M}) / \\
\text { Bausch } \\
\text { \& Lomb }\end{array}$} & T Cvintal & Brazil & 1 \\
\hline & S Esente & Italy & 2 \\
\hline & JP Gravel & Canada & 5 \\
\hline & A Ohrstrom & Sweden & 6 \\
\hline & J Sher & Canada & 7 \\
\hline & AS Sua & Philippines & 1 \\
\hline & & & Total 25 \\
\hline & $\mathrm{N}$ Anand & UK & 5 \\
\hline & E Assia & Israel & 1 \\
\hline & G Baikoff & France & 3 \\
\hline & M Dorner & Germany & 1 \\
\hline & A Frohn & Germany & 6 \\
\hline \multirow{12}{*}{$\begin{array}{l}\text { SC60B-OUV/ } \\
\text { Medical } \\
\text { Developmental } \\
\text { Research (MDR) }\end{array}$} & S Chawdhary & UK & 7 \\
\hline & C Chiquet & France & 1 \\
\hline & M Kaskaloglu & Turkey & 11 \\
\hline & R Kramer & Germany & 2 \\
\hline & Manufacturer & - & 9 \\
\hline & MF Pyfer & Pensylvania & 1 \\
\hline & M Soliman & Egypt & 2 \\
\hline & NP Strong & UK & 1 \\
\hline & E Williams & UK & 2 \\
\hline & Z Zhang & China & 2 \\
\hline & & & Total 54 \\
\hline & M Batterbury & UK & 1 \\
\hline \multirow{5}{*}{$\begin{array}{l}\text { Aqua-Sense/ } \\
\text { Ophthalmic } \\
\text { Innovations } \\
\text { International (OII) }\end{array}$} & S Chawdhary & UK & 1 \\
\hline & I Kozlowski & South Africa & 1 \\
\hline & SL de Luca & Brazil & 1 \\
\hline & W Troskie & South Africa & 4 \\
\hline & & & Total 8 \\
\hline
\end{tabular}

of the lenses was almost completely covered by those structures, giving them a 'frosty' and very reflective appearance. Nd:YAG laser was performed in many cases in an attempt to clean the optical surfaces, without success.

\section{SC60B-OUV $V^{\mathrm{TM}}$}

In the second group described here, the hydrophilic IOL to be recently associated with clinically significant postoperative optic opacification is the $\mathrm{SC} 60 \mathrm{~B}-\mathrm{OUV}^{\mathrm{TM}}$ 

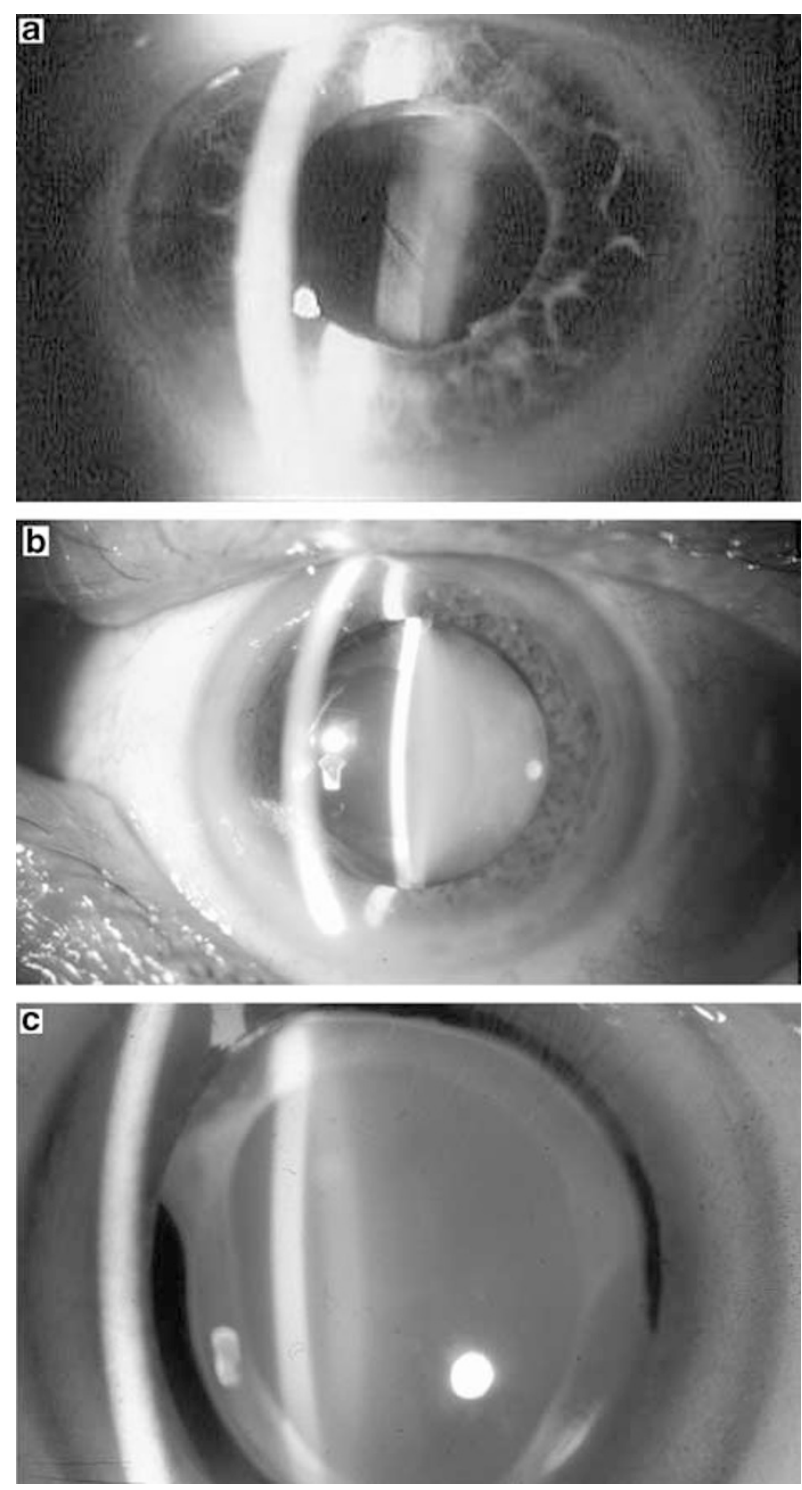

Figure 1 Slit-lamp photographs from patients implanted with hydrophilic acrylic lenses presenting whitish discoloration. (a) Note the haze or granularity present on the anterior surface of this Hydroview ${ }^{\mathrm{TM}}$ lens. Marks corresponding to forceps imprints can also be observed (courtesy: Dr Arne Öhrström, Sweden). (b) The opacity/haze of the optic of this SC60B$\mathrm{OUV}^{\mathrm{TM}}$ lens was observed 3 months postoperatively. The surgeon noted that the optic actually resembled a nuclear cataract (courtesy: Dr Mahmoud M Soliman, Egypt). (c) The intense opacity of this Aqua-Sense ${ }^{\mathrm{TM}}$ lens has also an aspect of nuclear cataract (courtesy: Dr Mark Batterbury and Aby Jacob, UK).

lens. The manufacturer and distributor of this design is Medical Developmental Research (MDR Inc., Clearwater, FL, USA). The material used for the manufacture of these IOLs is composed of a cross-linked copolymer of poly 2(hydroxyethyl methacrylate) (HEMA) and methyl methacrylate (MMA), with an incorporated UV absorber. The water content of this material is $28 \%$ and the refractive index is 1.46 . This is a one-piece design, so the haptics are manufactured from the same material as the optical component.

Since 1999 we analysed 54 explanted SC60B-OUV ${ }^{\mathrm{TM}}$ IOLs (Table 1) manufactured by MDR in our center. ${ }^{21-24}$ All of the lenses were explanted because of late postoperative opacification of the optic associated with decreased visual function. At the time of explantation, the ages of the patients ranged from 63 to 82 years (71.00 \pm 6.49$)$. Six patients were diabetic, but the majority of the patients did not have any known associated systemic or ocular conditions. The lenses were explanted from 7 to 32 months postoperatively $(19.63 \pm 7.63)$. In only two cases, the lens was explanted earlier than 1 year after the primary procedure (7 and 9 months). In general, the patients returned at around 12 months and later after the surgery complaining of a significant decrease in visual acuity (from 20/20 after the primary procedure to 20/200 in some cases). The clinical characteristics of these lenses were different from the previously described 'granularity' covering the optical surfaces of the Hydroview $^{\mathrm{TM}}$ design. The clinical appearance of the SC60B-OUV ${ }^{\mathrm{TM}}$ lenses was that of a clouding similar to a 'nuclear cataract' (Figure 1b).

\section{Aqua-Sense TM $^{\mathrm{TM}}$}

The third recent group of hydrophilic acrylic designs we analysed in our center because of whitish discoloration were explanted Aqua-Sense ${ }^{\mathrm{TM}}$ lenses, manufactured by Ophthalmic Innovations International, Inc. (OII), Ontario, CA, USA. ${ }^{29,30}$ This is also a one-piece lens, all manufactured from the same material, a hydrophilic acrylic copolymer with incorporated UV absorber. The material has a refractive index of 1.46 and a water content of $25 \%$. Although whitish discoloration was shown with all of the three designs, the intensity of the phenomenon with the AquaSense $^{\mathrm{TM}}$ is different. The opacity of the lenses available to us for analyses was much more severe than that associated with most cases of the two above-mentioned designs.

Since the beginning of 2001, we received eight Aqua-Sense $^{\mathrm{TM}}$ lenses (Table 1) in our laboratory. ${ }^{29,30}$ At the time of explantation, the age of the eight patients from this group ranged from 25 to 78 years $(58.29 \pm 16.85)$. Three patients were diabetic; the others were otherwise healthy. The lenses were explanted from 4 to 14 months postoperatively $(10.33 \pm 5.51)$ after the primary surgery. In only one case, the lens was explanted earlier than 1 year after the primary procedure (4 months). The visual acuity of the patients in 
general decreased from $20 / 20$ to $20 / 60$ after the primary procedure, with significant associated glare. The clinical appearance of the Aqua-Sense ${ }^{\mathrm{TM}}$ lenses was also that of a clouding similar to a 'nuclear cataract' (Figure 1c). As with the two above-mentioned designs, Nd:YAG laser was performed in some cases in an attempt to 'clean' the optical surfaces, without success.

\section{Analyses performed in our laboratory}

Once received in our center, the IOLs were immediately placed in $4 \%$ formaldehyde in $0.1 \mathrm{M}$ phosphate buffer, $\mathrm{pH}$ 7.4. Care was taken to avoid any manipulation of the IOLs' optics with forceps or other grasping instruments. Some lenses were bisected for explantation, and only one half of them were available to us.

Gross (macroscopic) analysis of the explanted IOLs was performed and gross pictures were taken using a camera (Nikon N905 AF, Nikon Corporation, Tokyo, Japan) fitted to an operating microscope (Leica/Wild MZ-8 Zoom Stereomicroscope, Vashaw Scientific, Inc., Norcross, GA, USA). The unstained lenses were then microscopically evaluated and photographed under a light microscope (Olympus, Optical Co. Ltd, Japan). They were rinsed in distilled water, immersed in a $1 \%$ alizarin red solution (a special stain for calcium) for $2 \mathrm{~min}$, rinsed again in distilled water and reexamined under the light microscope. ${ }^{31-33}$

We then performed full-thickness sections through the optic of the explanted lenses. Some of the resultant cylindrical blocks were directly stained with $1 \%$ alizarin red. The others were dehydrated and embedded in paraffin. Sagittal sections were performed and stained using the von Kossa method for calcium (staining with nitrate solution for $60 \mathrm{~min}$; exposure to a $100-\mathrm{W}$ lamp light; rinsing with distilled water; reaction with sodium thiosulphate solution for $2 \mathrm{~min}$; rinsing with distilled water; counterstaining in nuclear fast red solution for $5 \mathrm{~min}$ ). Calcium salts stain dark brown with this technique. $^{31-33}$

Some lenses in each group were air-dried at room temperature for 7 days, sputter-coated with aluminium and examined under a JEOL JSM 5410LV scanning electron microscope (SEM). The specimens were then further analysed by Dr DG Dunkelberger (Electron Microscopy Center of the University of South Carolina, Columbia, SC, USA) under a Hitachi 2500 Delta scanning electron microscope equipped with a Kevex X-ray detector with light element capabilities for energy-dispersive $X$-ray spectroscopic analyses (EDS).
Incisional biopsies of conjunctiva and iris were also obtained from one patient during removal and exchange of a Hydroview ${ }^{\mathrm{TM}}$ IOL. $^{13}$ This was done in order to rule out the presence of dystrophic calcification in those tissues.

\section{Gross and light microscopic analyses}

By gross and microscopic evaluations, the presence of granular deposits on the optical surfaces of the Hydroview $^{\mathrm{TM}}$ lenses was noted to cause different degrees of IOL haze/opacification, directly proportional to the amount of deposits and the surface of the lenses covered by them. In some cases, both optical surfaces were almost completely covered by a confluent granular layer, whereas in other cases some intervening clear areas were observed. Also, intervening clear areas, probably corresponding to marks caused by forceps during the folding process, were observed in all lenses (Figure 2a).

The optical surfaces and the haptics of the SC60B$\mathrm{OUV}^{\mathrm{TM}}$ lenses were in general free of deposits. However, there were multiple small structures initially noted to resemble 'glistenings' within the central $5 \mathrm{~mm}$ of the IOL optical component. These were found to be the cause of each lens opacification. The edges of the optics and the haptics appeared clear in the majority of the cases. However, in one case, the entire optical component and the haptics of the lens were completely opaque (SK Pandey, L Werner, DJ Apple, MM Kaskaloglu, N Anand, AM Izak et al. Different patterns of calcium precipitation in the optic and haptics of foldable hydrophilic acrylic lenses, presented at the ASCRS Symposium on Cataract, IOL and Refractive Surgery, San Diego, CA, 28 April 2001). ${ }^{24}$ Light microscopy demonstrated that the opacification was caused by the presence of multiple granular deposits within the optic component of the lenses, sometimes extending to the haptics (Figures $2 b-d$ ).

All of the Aqua-Sense ${ }^{\mathrm{TM}}$ lenses were completely opacified, presenting a bright whitish discoloration. Multiple, small granular deposits were observed on the external surfaces of the lenses, and also within their substance (optic and haptics; Figures 2e and f).

Multiple pits related to Nd:YAG laser treatments were also observed on the posterior surface of some of the IOLs in each group.

\section{Histochemical stainings}

The deposits on the surfaces of the Hydroview ${ }^{\mathrm{TM}}$ IOLs stained positive with alizarin red in all cases (Figures $3 a$ and $b$ ). No positive staining was observed on the haptics of the IOLs. Sagittal histological sections through the optic of this lens design, stained 

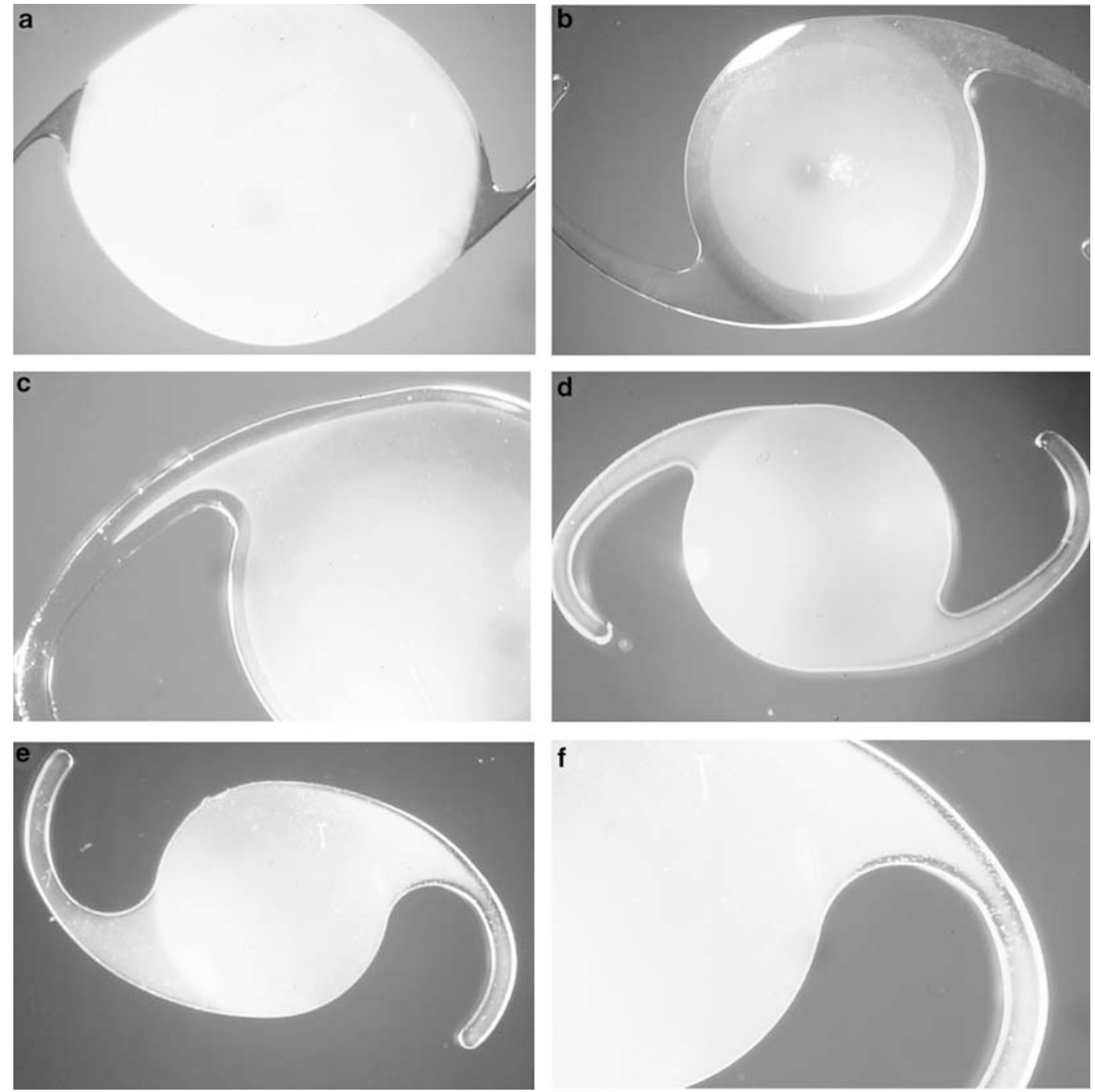

Figure 2 Gross photographs of explanted hydrophilic acrylic lenses presenting whitish discoloration, analysed in our center. (a) Hydroview ${ }^{\mathrm{TM}}$ lens with opacified optic. $(\mathrm{b}-\mathrm{d})$ different degrees of optic or optic/haptic opacification of SC60B-OUV ${ }^{\mathrm{TM}}$ lenses; (e, f) complete opacification of Aqua-Sense ${ }^{\mathrm{TM}}$ lenses.

using von Kossa's method, showed a continuous layer of dark brown, irregular granules on the anterior and posterior optical surfaces, and the edges of the lenses (Figures $3 c$ and d). Histochemical evaluations of the conjunctival and iris biopsies obtained from one of the patients were negative.

Alizarin red staining of the surfaces of the SC60B$\mathrm{OUV}^{\mathrm{TM}}$ lenses was in general negative. Analysis of the cut sections (sagittal view) of the lens optics revealed multiple granules of variable sizes in a region beneath the external anterior and posterior surfaces of the IOLs. The granules were distributed in a line parallel to the anterior and posterior curvatures of the optics. They stained positive with alizarin red (Figures $4 \mathrm{a}$ and b). Sagittal histological sections stained with the von Kossa method also confirmed the presence of multiple dark brown/black granules mostly concentrated in a region immediately beneath the anterior and posterior optical surfaces (Figures $4 \mathrm{c}$ and d).

Staining with alizarin red revealed spots of granular deposits on the external surfaces of the Aqua-Sense ${ }^{\mathrm{TM}}$ lenses. In some cases, a fine granularity was covering the lenses' external surfaces. Analysis of cut sections (sagittal view) of the lens optic revealed multiple granules of variable sizes in a region beneath the external anterior and posterior surfaces of the IOLs. As with the previous lens design, the granules were distributed in a line parallel to the anterior and posterior curvatures of the optics and they stained positive with alizarin red and the von Kossa method (Figure 5). 

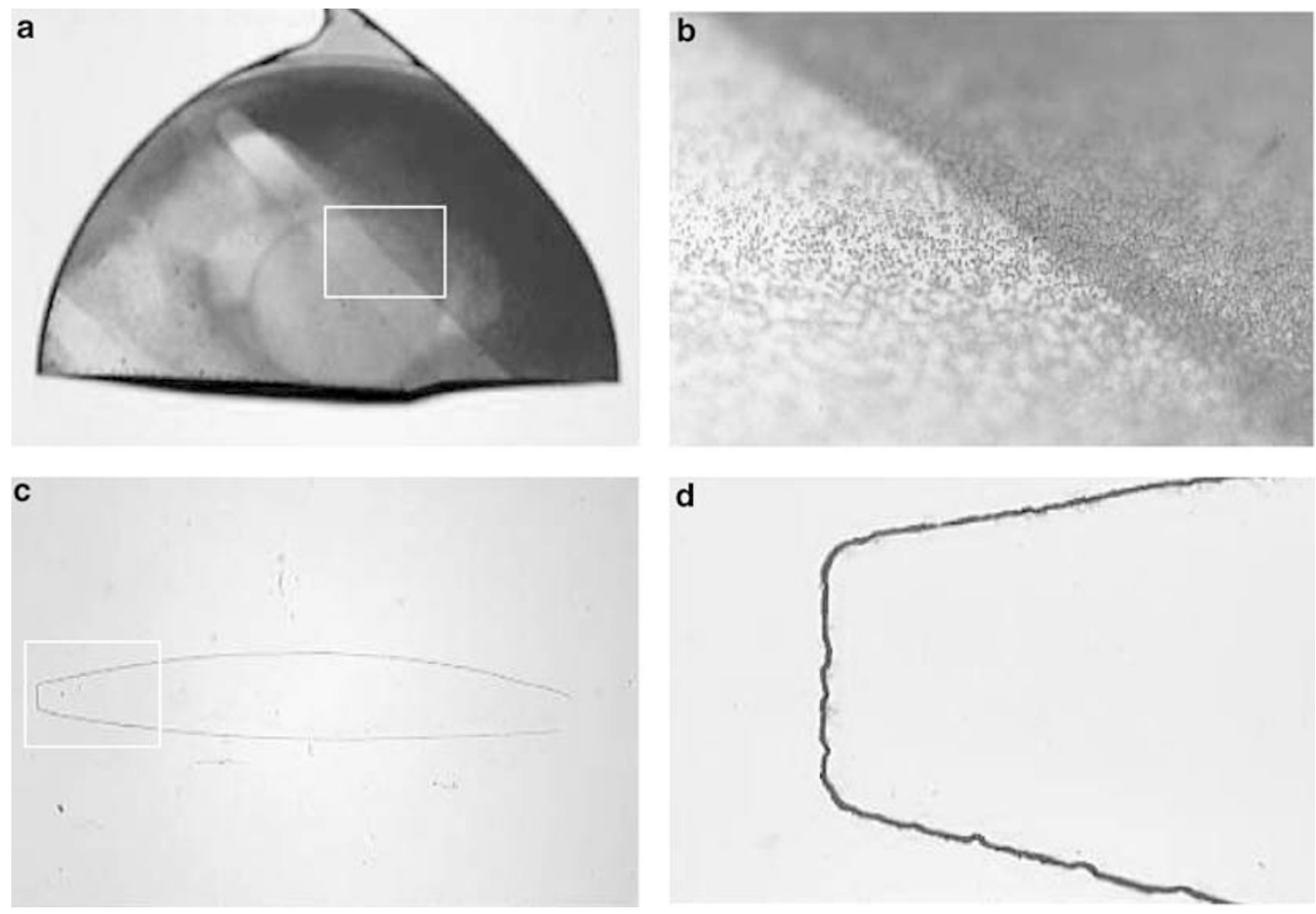

Figure 3 Histochemical analyses of explanted Hydroview ${ }^{\mathrm{TM}}$ lenses. $(\mathrm{a}, \mathrm{b})$ The deposits on the surface of the lens stained positive with alizarin red. Note the imprint of the forceps on the lens surface. Alizarin red stain; original magnification $\times 40$ and $\times 200$. (c, d) Sagittal sections of the lens optic. The lens material itself was dissolved during the preparation for histological examination, but the lens optic surface is delineated by a continuous layer of dark brown, irregular granules. Von Kossa's stain; original magnification $\times 40$ and $\times 200$.

\section{Scanning electron microscopy}

The aspect of the three lens designs observed under light microscopy was confirmed by SEM. Analyses of the anterior optical surfaces of some Hydroview ${ }^{\mathrm{TM}}$ lenses revealed granular deposits composed of multiple spherical-ovoid globules, scattered in some areas, and confluent in others (Figures 6a and b). SEM analysis of cut sections (sagittal view) of the optic of some SC60B$\mathrm{OUV}^{\mathrm{TM}}$ lenses confirmed that the region immediately subjacent to the IOLs' outer surfaces as well as the central area of the optical cut sections were free of deposits. This also revealed the presence of the granules in the intermediate region beneath the anterior and posterior surfaces (Figures $6 c$ and d). With the Aqua-Sense ${ }^{\mathrm{TM}}$ lenses, SEM of the anterior surface revealed the presence of small granular deposits (Figures 7a and b). Analyses of cut sections of this lens design demonstrated features similar to those described with the SC60B-OUV ${ }^{\mathrm{TM}}$ lens (Figures 7c and d).

\section{Energy-dispersive X-ray spectroscopy}

With the three lens designs, EDS performed precisely on the deposits revealed the presence of calcium and phosphate peaks (Figure 8a). EDS was also performed on areas free of deposits to serve as controls, showing only peaks of carbon and oxygen (Figure $8 b$ ).

\section{Possible factors involved in the pathological mechanism}

We can divide the phenomenon of crystalline deposition on IOL optics into two general time frames: intra or shortly postoperative $v$ s late postoperative (circa 12 months).

Jensen $e a^{34}$ in 1994 first described the formation of crystalline deposits on the surface of IOLs during cataract surgery in a series of 11 patients. The deposits would last a long time (at least 6 months) if sequestered by the posterior capsule, and they had a significant effect on the visual acuity (20/40 or worse). The common features in all cases were the use of Healon GV ${ }^{\circledR}$ (Pharmacia-Upjohn Ophthalmics,

Kalamazoo, MI, USA), a high-molecular-weight hyaluronate sodium, and BSS ${ }^{\circledR}$ or BSS Plus ${ }^{\circledR}$ (Alcon Surgical, Inc., Forth Worth, TX, USA). The authors hypothesized that the phosphate components used in the viscoelastic preparations to buffer the 

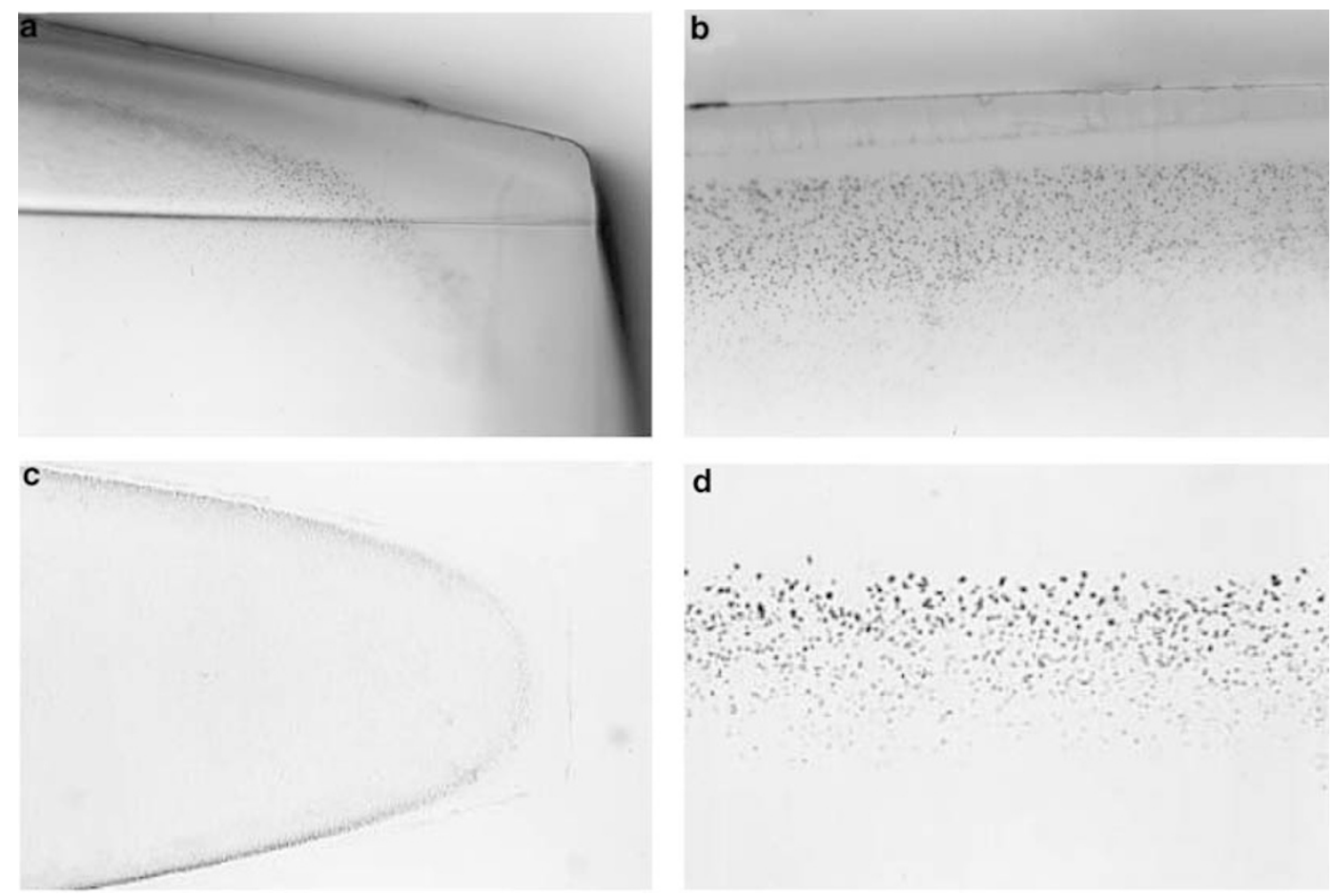

Figure 4 Photomicrographs of cut sections of the lens optic of SC60B-OUV ${ }^{\mathrm{TM}}$ lenses showing the distribution of the deposits within their substance, demonstrated by histochemical methods. (a, b) Alizarin red stain; original magnification $\times 100$ and $\times 200$; (c, d) Von Kossa's stain; original magnification $\times 40$ and $\times 400$.

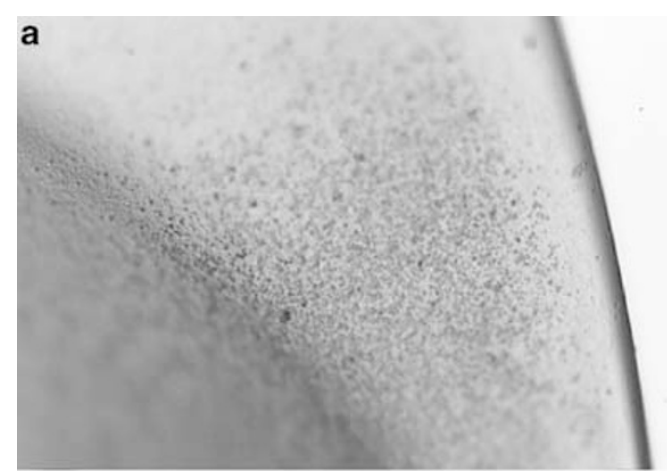

C

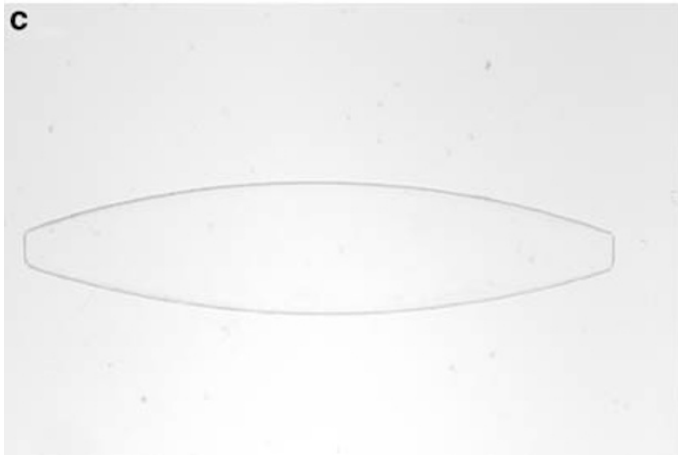

b

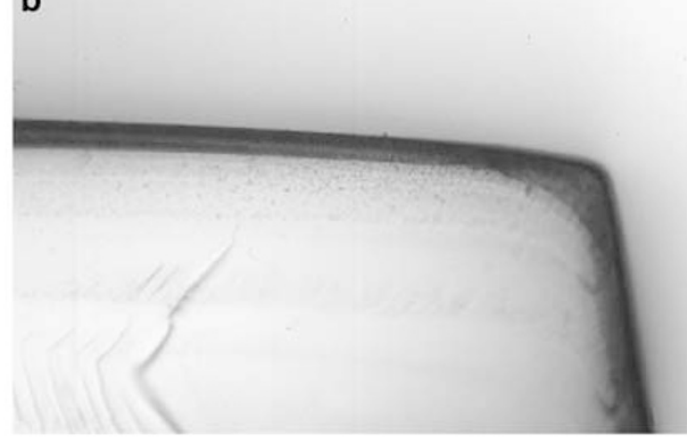

d

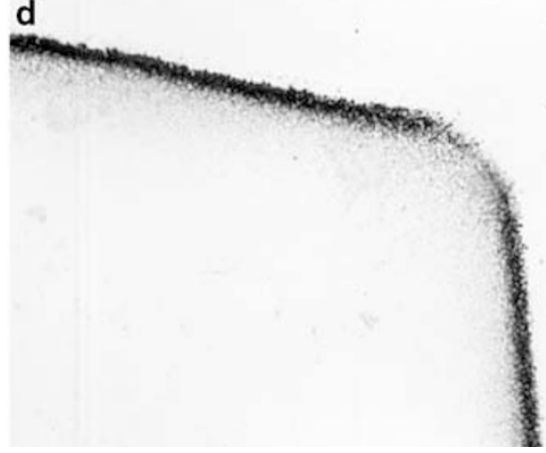

Figure 5 Photomicrographs of the anterior surface and from cut sections of the lens optic of one explanted Aqua-Sense ${ }^{\mathrm{TM}}$ lens, showing the distribution of the deposits on its surface and within its substance, demonstrated by histochemical methods. (a, b) alizarin red stain; original magnification $\times 40$ and $\times 100$; (c, d) von Kossa's stain; original magnification $\times 40$ and $\times 200$. 

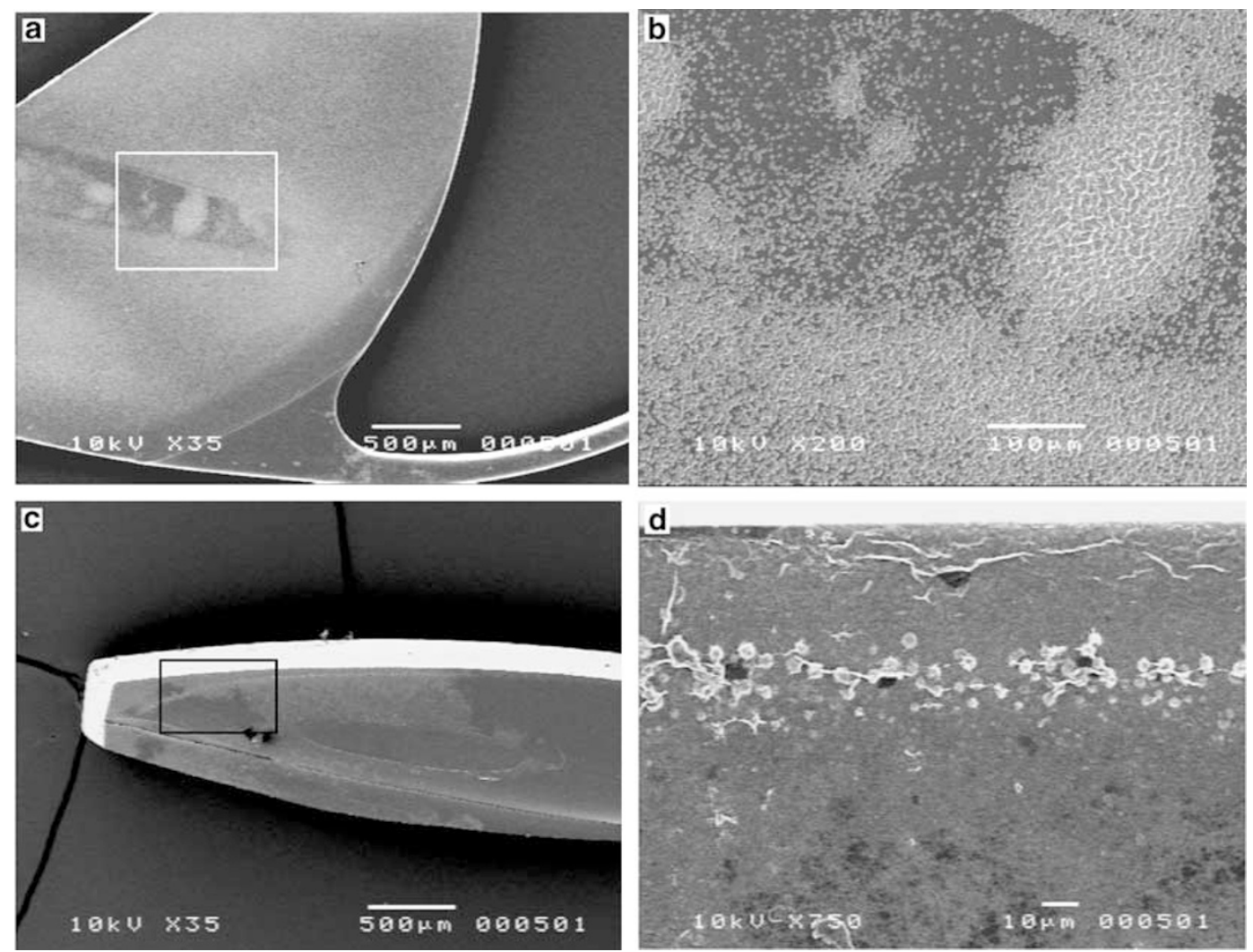

Figure 6 Scanning electron microscopic analyses of hydrophilic acrylic lenses explanted because of whitish discolouration. (a, b) deposits on the anterior surface of a Hydroview ${ }^{\mathrm{TM}}$ lens. They are scattered in some areas and confluent in others. (c, d) deposits within the optic substance of an SC60B-OUV ${ }^{\mathrm{TM}}$ lens. They are distributed in a line parallel to the external optical surfaces, but absent in the central part of the optic.

solution could have reacted with calcium from irrigating solutions or the aqueous humor of the patients, and precipitated. Nevertheless, no analysis of the deposits was performed. Although they were also noted on PMMA IOLs, the severe cases were all associated with silicone lenses, suggesting that silicone is a better substrate for this phenomenon. The same group described later 22 other cases of intraoperative crystallization on IOL surfaces. ${ }^{35,36}$ Again, all the severe cases were associated with silicone lenses, but viscoelastics other than Healon $\mathrm{GV}^{\circledR}$ have also been used. In these studies, a sample of the material was submitted to SEM analysis and $\mathrm{X}$-ray photoelectron spectroscopy, for elemental identification. The cation of concern was found to be calcium.

Crystalline precipitation on the surface of hydrogel lenses with water content higher than Hydroview ${ }^{\mathrm{TM}}$ lenses (Iogel 1103, Alcon Laboratories, Fort Worth, TX, USA) was first described by Amon and Menapace in $1991 .{ }^{37,38}$ They evaluated in vivo the surfaces of 200 consecutive IOLs over a 1.5-year postoperative period. In their study, the presence of few, dust-like white precipitates of unknown origin on the surface of $7 \%$ of the lenses was described. Nevertheless, no comment was made on the time of presentation and the evolution of the deposits.

Bucher $e a^{39}$ in 1995 reported a case of dystrophic calcification of the same hydrogel IOL, in an 80-year-old woman with chronic lymphatic leukaemia. On the first postoperative day, a brown-white material was observed behind the IOL. During the second postoperative month, the material turned white and changed its shape. Two months after the surgery, granular whitish spots appeared on the anterior surface of the IOL. Their confluence with time formed a band-shaped white layer on the anterior optic surface. White granules also developed in the corneal stroma at the site of a paracentesis, but not at the incision. The lens was explanted because of decreased visual acuity. Special staining and surface analyses revealed the material to contain calcium hydroxyapatite. Intraocular solutions used during the surgery in this case were Ringer's lactate with epinephrine, sodium hyaluronate as viscoelastic, 

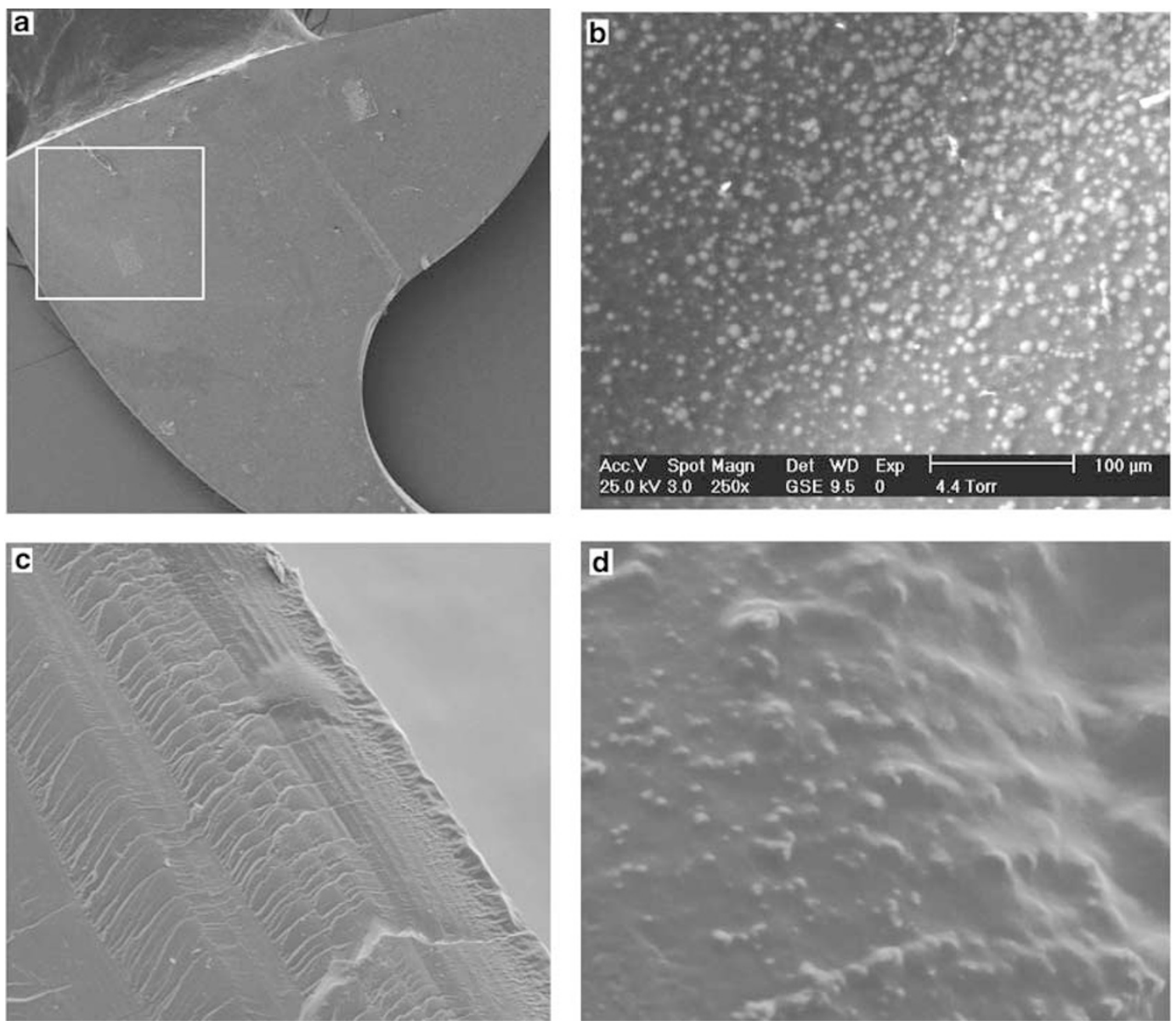

Figure 7 Scanning electron microscopic analyses of an explanted Aqua-Sense ${ }^{\mathrm{TM}}$ lens. $(\mathrm{a}, \mathrm{b})$ deposits on the anterior surface of the lens. (c, d) deposits within the optic substance of the lens, also distributed in a line parallel to the external optical surfaces.

and thymoxamine, which is a phosphate-buffered, solution used to achieve miosis. Although the patient had chronic lymphatic leukaemia, no disturbance of calcium metabolism was detected and the electrolyte levels were normal on several occasions before and after the development of calcification. The authors hypothesized that an oversupply of calcium, from residual lens material, and of phosphates, from the thymoxamine solution, reacted originating the deposits.

All the previous reports concerning crystalline deposit formation on IOL surfaces, mostly in the early postoperative period, seem to be related to calcium-phosphate reaction with the formation of calcium salts. ${ }^{34-39}$ Indeed, hydroxyapatite is the thermodynamically stable phase of calcium phosphate in biological systems. Calcium and phosphate are present in blood and interstitial fluids at levels that nearly exceed their solubility product. Although the calcium content of the normal aqueous humor is low, about half that of the serum, any cause of a localized increase in calcium or phosphate, such as intraocular inflammation or administration of intraocular drugs rich in these elements, might result in dystrophic calcification. ${ }^{40-42}$ Some studies reported corneal calciumphosphate precipitates related to the phosphate buffer concentration in Viscoat ${ }^{\mathbb{B}}$ (Alcon Laboratories, Fort Worth, TX, USA). ${ }^{40,41}$ Viscoat ${ }^{\circledR}$ is a specific formulation of chondroitin sulphate and sodium hyaluronate dissolved in isotonic physiological phosphate-buffered solution. ${ }^{43}$ The phosphate buffer concentration was reduced since these reports, in order to prevent the precipitation phenomenon. The crystalline lens itself (or residual cortical material) is a potential source of phosphates. Sources of calcium in the cataract surgery scenario could be represented by aqueous humor, intraocular irrigating solutions, and also by crystalline lens. Indeed, the concentration of calcium adsorbed to lens proteins is high.

We decided to start the tests by using the alizarin red staining technique. This method is very simple to perform and it is one of the most specific. Demonstration 

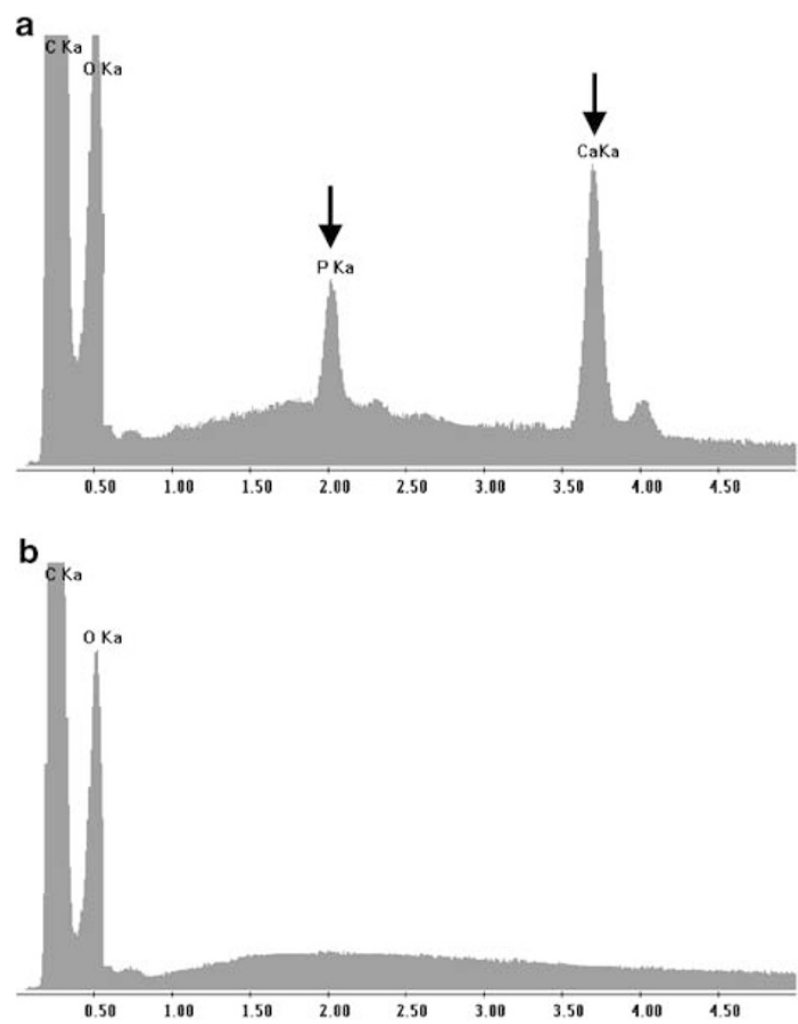

Figure 8 Energy dispersive X-ray spectroscopic analyses of a cut section (sagittal view) of the IOL optic of an explanted AquaSense ${ }^{\mathrm{TM}}$ lens. (a) Spectrum obtained from the deposits within the substance of the lens. Note the peaks of calcium and phosphate (arrows). (b) Spectrum obtained from the central part of the optic, without deposits.

of calcium with this anthraquinone-derivative dye depends on a chelation process with the dye. ${ }^{31,32}$ The von Kossa silver test demonstrates the presence of calcium through a metal-substitution technique. ${ }^{33}$ This method confirmed our findings with alizarin red. Later, SEM and EDS analyses revealed the deposits to be composed of calcium and phosphates.

Calcium deposition observed in our cases occurred in the late postoperative period. In the cases of surface deposition, one might speculate that it is similar to the calcium deposition associated with spoilation of soft contact lenses. The term spoilation is used to describe physical and chemical changes in the nature of the hydrophilic soft contact lenses and various deposits that may impair their optical properties and produce discomfort and intolerance. Contact lens spoilage may occur in some cases as early as in $48 \mathrm{~h}$ of wear, but in the majority of cases it occurs after 3-6 months of daily or extended wear. Filmy deposits on the surface of soft contact lenses are in general represented by protein, calcium, lipid and/or bacterial components. Factors that may predispose the formation of calcium deposits on soft contact lenses include dry-eye syndrome, increased levels of calcium and phosphate in the tears, and inflammation. In addition to producing a film, calcium can form chalky white granules that may take the shape of barnacles with concentric rings or lamellae. They resemble rock formations and exhibit birefringence under polarized light. ${ }^{44-49}$

Heavy inorganic films often cause damage to the soft contact lens surface, since the material may penetrate into the lens matrix. Thus, after chemical removal of the deposits, pits and other irregularities usually remain. ${ }^{47,48}$ In the case of Hydroview ${ }^{\mathrm{TM}}$ IOLs, chemical removal of calcium phosphate revealed the presence of few small pits and fissures at SEM, which were found to be artefactual rather than permanent damage caused by the deposits on the IOL surfaces (George Green, February 2000, PhD at Bausch and Lomb, personal communication). Yu et $a l^{14,15}$ and Groh et $a l_{,}^{16}$ in transmission electron analyses of this same lens design, found calcium precipitates within the lens substance, in a region immediately subjacent to the external surfaces.

Chang $e t a l^{5}$ published the first clinical report on late postoperative opacification of the second group of lenses (SC60B-OUV ${ }^{\mathrm{TM}} \mathrm{IOL}$ ), when they noted a central clouding associated with a decrease in visual acuity. No inflammatory reaction was observed. They speculated whether the IOL opacity could be caused by a process similar to the 'glistenings' associated with a hydrophobic acrylic lens, the Alcon AcrySof ${ }^{\mathrm{TM}} .{ }^{50-52}$ We had a similar impression after our initial gross and light microscopic examinations of these lenses. However, the clinical profile noted with the AcrySof ${ }^{\mathrm{TM}}$ IOL is different. The occurrence of Alcon AcrySof ${ }^{\mathrm{TM}}$ related glistenings has been described as early as 1 week after cataract surgery, and the time frame is highly variable, as opposed to at around 24 months with the SC60B-OUV ${ }^{\mathrm{TM}}$ IOLs. Clinical studies on the AcrySof ${ }^{\mathrm{TM}}$ IOL have demonstrated that contrast sensitivity has been decreased in some patients, but clinically significant decrease on visual acuity has been rare. ${ }^{50}$ In vitro studies have suggested that the occurrence of glistenings in AcrySof ${ }^{\mathrm{TM}}$ IOLs may be related to variations in the temperature $(\Delta t)$, with the formation of vacuoles within the submersed acrylic polymer when there is a transient increase in temperature above the glass transition temperature, approximately $18.5^{\circ} \mathrm{C}$ for AcrySof $^{\mathrm{TM}}$ (DJ Apple, Clinicopathological correlation of vacuoles in an acrylic IOL, Best Paper of the Session, presented at the ASCRS Symposium on Cataract, IOL and Refractive Surgery, San Diego, CA, USA, April 1998). 'Glistenings' may then subsequently form from anterior chamber fluid. It has been reported that the IOL packaging, the AcryPak ${ }^{\mathrm{TM}}$, and the sterilization technique used with that system may have made the IOL 
susceptible to the micro-vacuole formation. In vitro studies have also demonstrated that the temperature at which the IOLs were stored and shipped in the dry state had no influence on the 'glistenings' and was thus unrelated to this phenomenon. ${ }^{51}$

In contrast to the findings of what morphologically resembled 'glistenings' noted in these clinical and in vitro analyses, light microscopic analyses of the cut sections of the optics (sagittal views) revealed that the structures causing the opacification with the SC60B-OUV ${ }^{\mathrm{TM}}$ lenses are not fluid-filled vacuoles, but rather granules of variable sizes. Frohn, Dick, and co-workers have evaluated 41 of these lenses by light microscopy, high-performance liquid chromatography, sodium dodecyl sulphate polyacrylamide gel electrophoresis, spectrometric analysis, and autoclaving. Neither fatty acids nor proteins could be identified within the IOLs. Spectrometric analysis yielded absorption peaks in the ultraviolet (UV) spectral range. According to the same authors, these findings indicate premature ageing of the UV blocking agent within the lenses, the source of the opacification being a change in the IOL material itself. Indeed, the material of these IOLs does contain an incorporated UV absorber, which functions to protect the retina from UV radiation in the $300-400 \mathrm{~nm}$ range, protection normally provided by the crystalline lens. We have not yet carried out studies to verify Frohn's and Dick's findings that unbound UV-absorber monomers or any impurity causes opacification within the IOL optic. Their findings and the calcification process demonstrated by us may be correlated, although our data do not allow us to make definitive conclusions.

There have been reports on brownish discoloration and central haze of silicone lenses, both in the early 1990s as well as recently (RR Schulze, DJ Apple. Progressive pigmentation of Staar silicone IOLs: Case report, presented at the ASCRS Symposium on Cataract, IOL and Refractive Surgery, Boston, MA, USA, 20-24 May 2000). ${ }^{53-55}$ This complication has been generally observed in the early postoperative period, for example, around 6 weeks after cataract surgery and IOL implantation. In general, it is clinically insignificant; IOL explantation has rarely been performed. These reports have suggested that the brown haze was because of light scatter from water vapour that may diffuse into the silicone when immersed in an aqueous medium. This may be caused by some anomaly of the curing process during the manufacture of those lenses or by incomplete extraction of large polymers. UV blocking agents did not seem to be an issue with lens discoloration since the phenomenon was also observed with silicone IOL models not containing these agents. Additional filtration steps in the manufacturing process of silicone lenses seemed to solve the problem. Chromatographic detection and characterization of unbound constituents of the SC60B$\mathrm{OUV}^{\mathrm{TM}}$ lenses should be performed to address this issue with this IOL.

Dr Mahmut Kaskaloglu (Turkey) has implanted 361 of these lenses between November 1997 and October 1999. He observed 18 cases of late postoperative opacification of the SC60B-OUV DJ ${ }^{\mathrm{TM}}$ lens, nine of which had associated visual symptoms sufficient to justify explantation and submit for pathological analysis. Of the 18 cases of opacification, five patients were diabetic (two explantations) (MM Kaskaloglu, L Werner, Visual outcomes of the patients with an opacified hydrophilic acrylic IOL, presented at the ASCRS Symposium on Cataract, IOL and Refractive Surgery, Best Paper of the Session, San Diego, CA, 29 April, 2001). ${ }^{24}$ To date there is no means to establish a definitive relationship between diabetes and this complication. Again, three separate tests strongly suggested that the granules are at least in part composed of calcium - the alizarin red stain, the von Kossa stain and SEM analyses with EDS. EDS demonstrated the presence of calcium peaks only at the level of the deposits, not in the centre of the optic and not in the region immediately subjacent to the surface. Interestingly, although the SC60B-OUV ${ }^{\mathrm{TM}}$ design is a single-piece lens entirely manufactured from a single acrylic material, the opacifying granules were present only in a specific region of the IOLs' optic. The reasons for this pattern are still unknown to us. It may represent a diffusion-type pattern or absorption of material from aqueous humor.

The Aqua-Sense ${ }^{\mathrm{TM}} \mathrm{IOL}$ design represents the third group of such cases. Calcium deposition on the external surface of the lens as well as within the substance of the optic and haptic components has been observed with all Aqua-Sense ${ }^{\mathrm{TM}}$ lenses analysed in our center. ${ }^{29,30}$

Dr Wynand Troskie (South Africa) has implanted 187 of these lenses between August 1999 and October 2000. Thus far as of the time of this writing, he has observed 23 cases of postoperative opacification of the Aqua-Sense $^{\mathrm{TM}}$ lens, 16 of which had associated visual symptoms sufficient to justify explantation and submit the explants for pathological analysis. Of the 23 cases of opacification, four patients were diabetic (three explantations). The Aqua-Sense ${ }^{\mathrm{TM}}$ lenses analysed by us revealed a total opacification occurring to an extent that we have never seen since we began examining IOLs in 1983.

At the time of this writing, the number of reported cases with the Hydroview ${ }^{\mathrm{TM}}$ lens is relatively small. 309 of approximately 400000 lenses implanted worldwide. In 96 cases, the IOL changes were clinically significant, decreasing patient vision enough to result in lens 
explantation. The clinical reports have not been randomly distributed. Although this IOL model has been implanted in 3500 centres worldwide, reports have appeared in clusters. The vast majority has come from 31 ophthalmic practices in 11 countries. We have studied cases from several of these centres, including practices in Australia, Canada, and Sweden.

In a February 2001 letter to surgeons who have implanted the Hydroview ${ }^{\mathrm{TM}}$ IOL, Bausch and Lomb described their investigation into the phenomenon. Surface chemistry studies identified the lens deposits as a layered mixture of octacalcium phosphate, fatty acids, salts, and small amounts of silicone (C Guttman, Hydroview calcification resolved, Ophthalmology Times, 2001; 26(4). An in vitro model was then constructed to find out how the material deposited onto the lens. This model, according to the manufacturer, revealed a migration of silicone from a gasket in the lens packaging onto the surface of the IOL. The models also showed that in addition to silicone, fatty acids had to be present to attract calcium ions to the lens surface. A separate retrospective clinical case/ control study was also conducted by the manufacturer at the sites where the highest incidences of calcification were reported. A compromised blood-retinal barrier seemed to be associated with the appearance of calcified deposits.

No reports of presumed calcification were received prior to introduction of the SureFold ${ }^{\circledR}$ system. According to Bausch and Lomb studies, part of the components of this packaging contains silicone, which may come off the packaging onto the lens optic. It then appears to be a catalyst for calcium precipitation. Fatty acids and silicone, perhaps in association with a metabolic disease in the affected patient, could result in the calcification.

As of May 2000, MDR had announced 56 cases of late postoperative lens opacification out of over 75000 SC60B$\mathrm{OUV}^{\mathrm{TM}}$ lenses implanted worldwide. They were aware of at least 20 other cases that required explantation because of significant visual loss, in addition to those described here. The manufacturer has withdrawn all SC60B-OUV ${ }^{\mathrm{TM}}$ IOLs that have been fabricated from material obtained from their previous polymer supplier and have sent in June of 2000 an informational letter to all lens users. All of these IOLs are now being manufactured from polymer material obtained from a new source.

The manufacturer of the Aqua-Sense ${ }^{\mathrm{TM}}$ lens has reported 12 similar cases, besides the cases described here (Mr Rick Aguilera, President OII, personal communication, Amsterdam, The Netherlands, September 2001). The manufacturer also stated that researchers have found silicone particles on the surface of the lenses. The silicone contaminants appeared to come from some components of the IOL packaging. Those silicone components have been removed and changed to Teflon. Also, the manufacturer stated that they have implemented new manufacturing processes involving proprietary technology to minimize exposure of in-process lenses to chemical agents and remove any residual of these substances during the final stages of manufacture. Residual water-soluble process compounds are now extracted before packaging and sterilization by a process OII named the P.U.R.E ${ }^{\mathrm{TM}}$ system (Precision UnResolved-materials Extraction). The Aqua-Sense ${ }^{\mathrm{TM}}$ IOL was then re-released in January 2001.

\section{Prevention and treatment}

The opacification described in our reports has an entirely different appearance than classic posterior capsule opacification or anterior lens epithelial cell proliferation.

It is important for the surgeons who implanted lenses from these three groups to recognize this condition. Excessive Nd:YAG laser treatment, in an attempt to clean the optical surfaces of the lenses, may jeopardize implantation of a new lens in the capsular bag after explantation of the opacified lens. The adherence of the deposits to the optical surfaces of the lenses seems to be extremely strong and Nd:YAG laser treatment was proven to be ineffective in the cleaning of the lenses' surfaces. The cause of this condition seems to be multifactorial, and until the pathogenic mechanism is not fully clarified, explantation and exchange of the IOL is the only available treatment. For the lens explantation, one small radial incision may be performed at the edge of the capsulorhexis, so its diameter can be increased. It is very important to well viscodissect the lens from the capsular bag, in order to liberate any adherence to this structure. The lens is removed after being folded inside the eye, bisected, or intact through a larger incision. The status of the capsular bag should then be carefully inspected, which will influence the decision about the site for fixation of the new lens. Methods for the prevention of this condition are also not completely defined to date. Long-term clinical studies will determine the efficacy of modifications performed on IOL polymers and packaging for prevention of lens calcification.

\section{Summary}

Each hydrophilic acrylic IOL design available in the market is manufactured from a different copolymer acrylic. To the best of our knowledge, the calcification problem described in this text cannot be generalized to all of the lenses in this category. The incidence of IOL explantation because of calcification remains low, much 
less than $1 \%$ in each of the three groups described here. The mechanism is not fully understood, but it does not seem to be directly related to substances used during the surgery as it occurred in the late postoperative period. Also, the substances used during the surgery were not the same in all cases. The majority of the patients involved had an associated systemic disease; therefore, the possibility of a patient-related factor, such as a metabolic imbalance, cannot be ruled out.

Lot history, component history, process changes, surgical setting and techniques, environmental factors, pre-existing patients conditions, and packaging have been examined. It is now important to carefully follow clinical outcomes of these lens designs in order to ensure if this phenomenon will disappear following the changes in polymer source or packaging.

\section{Acknowledgements}

We thank all the ophthalmic surgeons around the world who submitted explanted hydrogel intraocular lenses for pathological analysis to our centre.

The authors have no financial or proprietary interest in any product mentioned in this paper. This work was supported in part by an unrestricted grant from Research to Prevent Blindness, Inc., New York, NY, USA.

\section{References}

1 Christ FR, Buchen SY, Deacon J, Cunanan CM, Giamporcaro JE, Knight PM. Biomaterials used for intraocular lenses. In: Wise DL, Trantolo DJ, Altobelli DE et al (eds). Encyclopedic Handbook of Biomaterials and Bioengineering. Part B: Applications, Vol 2. Marcel Dekker, Inc.: New York, NY, 1995, pp 1261-1313.

2 Chehade M, Elder MJ. Intraocular lens materials and styles: a review. Aust NZ J Ophthalmol 1997; 25: 255-263.

3 Schauersberger J, Kruger A, Abela C, Mullner-Eidenbock A, Petternel V, Svolba G. Course of postoperative inflammation after implantation of 4 types of foldable intraocular lenses. J Cataract Refract Surg 1999; 25: 1116-1120.

4 Hollick EJ, Spalton DJ, Ursell PG. Surface cytologic features on intraocular lenses: can increased biocompatibility have disadvantages? Arch Ophthalmol 1999; 117: 872-878.

5 Chang BYP, Davey KG, Gupta M, Hutchinson C. Late clouding of an acrylic intraocular lens following routine phacoemulsification. Eye 1999; 13: 807-808.

6 Murray RI. Two cases of late opacification of the hydroview hydrogel intraocular lens. J Catract Refract Surg 2000; 26: 1272-1273

7 Fernando GT, Crayford BB. Visually significant calcification of hydrogel intraocular lenses necessitating explantation. Clin Exp Ophthalmol 2000; 28: 280-286.

8 Apple DJ, Werner L, Escobar-Gomez M, Pandey SK. Deposits on the optical surfaces of Hydroview intraocular lenses (letter). J Cataract Refract Surg 2000; 26: 796-797.

9 Werner L, Apple DJ, Escobar-Gomez M, Ohrstrom A, Crayford BB, Bianchi R et al. Postoperative deposition of calcium on the surfaces of a hydrogel intraocular lens. Ophthalmology 2000; 107: 2179-2185.

10 Izak A, Werner L, Pandey SK, Macky TA, Trivedi RH, Apple DJ. Calcification on the surface of the Bausch \& Lomb Hydroview ${ }^{\mathrm{TM}}$ intraocular lens. In: Werner L, Apple DJ (eds). Complications of Aphakic and Refractive Intraocular Lenses. Int Ophthalmol Clin, Vol 41. Lippincott, Williams \& Wilkins: Philadelphia, PA, 2001, pp 62-78.

11 Apple DJ, Werner L, Pandey SK. Newly recognized complications of posterior chamber intraocular lenses (Editorial). Arch Ophthalmol 2001; 119: 581-582.

12 Apple DJ, Werner L. Complications of cataract and refractive surgery: a clinicopathological documentation. Trans Am Ophthalmol Soc 2001; 99: 95-107; discusion 107-109.

13 Pandey SK, Werner L, Apple DJ, Gravel JP. Calcium precipitation on the optical surfaces of a foldable intraocular lens: a clinicopathological correlation. Arch Ophthalmol 2002 (in press).

14 Yu AFK, Shek TWH. Hydroxyapatite formation on implanted hydrogel intraocular lenses. Arch Ophthalmol 2001; 107: 2179-2185.

15 Yu AKF, Kwan KYW, Chan DHY, Fong DYT. Clinical features of 46 eyes with calcified hydrogel intraocular lenses. J Cataract Refract Surg 2001; 27: 1596-1606.

16 Groh JMM, Schlotzer-Schrehardt U, Rummelt C, von Below H, Kuchle M. Postoperative KunstlinsenEintrubungen bei 12 Hydrogel-Intraokularlinsen (Hydroview). Klin Monatsbl Augenheilkd 2001; 218: 645-648.

17 Shek TW, Wong A, Yau B, Yu Ak. Opacification of artificial intraocular lens: an electron microscopic study. Ultrastruct Pathol 2001; 25: 281-283.

18 Buchen SY, Cunanan CM, Gwon A, Weinschenk J 3rd, Gruben L, Knight PM. Assessing intraocular lens calcification in an animal model. J Cataract Refract Surg 2001; 27: 1473-1484.

19 Frohn A, Dick B, Augustin AJ, Grus FH. Late opacification of the foldable hydrophilic acrylic lens SC60B-OUV. Ophthalmology 2001; 108: 1999-2004.

20 Mamalis N. Hydrophilic acrylic intraocular lenses (Editorial). J Cataract Refract Surg 2001; 27: 1339-1340.

21 Werner L, Apple DJ, Kaskaloglu M, Pandey SK. Dense opacification of the optical component of a hydrophilic intraocular lens: a clinicopathological analysis of 9 explanted lenses. J Cataract Refract Surg 2001; 27: 1485-1492.

22 Macky TA, Trivedi RH, Werner L, Pandey SK, Izak AM, Apple DJ. Degeneration of UV absorber material and calcium deposits within the optic of a hydrophilic IOL lens (manufactured by Medical Developmental Research). In: Werner L, Apple DJ (eds). Complications of Aphakic and Refractive Intraocular Lenses. Int Ophthalmol Clin, Vol 41. Lippincott, Williams \& Wilkins: Philadelphia, PA, 2001, pp 79-90.

23 Apple DJ, Werner L, Pandey SK. Opalescence of hydrophilic acrylic lenses (letter). Eye 2001; 15: 97-98.

24 Pandey SK, Werner L, Apple DJ, Kaskaloglu MM. Hydrophilic acrylic intraocular lens optic and haptics opacification in a diabetic patient: bilateral case report and clinicopathological correlation. Ophthalmology 2002 (submitted).

25 Sharma TK, Chawdhary S. The opalescence of hydrogel intraocular lens. Eye 2001; 15: 97-98. 
26 Sharma A, Ram J, Gupta A. Late clouding of an acrylic intraocular lens following routine phacoemulsification (letter). Eye 2001; 15: 361.

27 Woodruff SA, Khan J, Dhingra N, Gashau I, Chawdhary S. Late clouding of an acrylic intraocular lens following routine phacoemulsification (letter). Eye 2001; 15: 361-362.

28 Pavlovic S, Magdowski G, Brueckel B, Pavlovic S. Ultrastructural analysis of opacities seen in a hydrophilic acrylic intracular lens. Eye 2001; 15: 657-659.

29 Werner L, Apple DJ, Izak AM. Discoloration/opacification of modern foldable hydrogel intraocular lens designs. In: Buratto L, Werner L, Zanini M, Apple DJ (eds). Phacoemulsification: Principles and Techniques. Slack Inc.: Thorofare, NJ, 2002 (in press).

30 Werner L, Izak AM, Apple DJ, Pandey SK, Troskie W et al. Complete calcification of a hydrogel lens design: case reports and clinicopathological correlation. Am J Ophthalmol 2002 (submitted).

31 McGee Russell SM. Histochemical methods for calcium. J Histochem Cytochem 1958; 6: 22-42.

32 Carr LB, Rambo ON, Feichtmeir TV. A method of demonstrating calcium in tissue sections using chloranilic acid. J Histochem Cytochem 1961; 9: 415-417.

33 Pizzolato P. Histochemical recognition of calcium oxalate. I Histochem Cytochem 1964; 12: 333-336.

34 Jensen MK, Crandall AS, Mamalis N, Olson RJ. Crystallization on intraocular lens surfaces associated with the use of Healon GV. Arch Ophthalmol 1994; 112: 1037-1042.

35 Olson RJ. New cases of crystalline deposits on intraocular lenses not related to any specific viscoelastic (letter). Arch Ophthalmol 1995; 113: 1229.

36 Olson RJ, Caldwell KD, Crandall AS, Jensen MK, Huang SC, Intraoperative crystallization on the intraocular lens surface. Am J Ophthalmol 1998; 126: 177-184.

37 Amon M, Menapace R. Cellular invasion on hydrogel and poly(methyl methacrylate) implants: an in vivo study. J Cataract Refract Surg 1991; 17: 774-779.

38 Amon M, Menapace R. In vivo observation of surface precipitates of 200 consecutive hydrogel intraocular lenses. Ophthalmologica 1992; 204: 13-18.

39 Bucher PJM, Buchi ER, Daicker BC. Dystrophic calcification of an implanted hydroxyethylmethacrylate intraocular lens. Arch Ophthalmol 1995; 113: 1431-1435.

40 Ullman S, Lichtenstein SB, Heerlein K. Corneal opacities secondary to Viscoat ${ }^{\mathbb{R}}$. J Cataract Refract Surg 1986; 12 $489-492$.
41 Binder PS, Deg JK, Kohl FS. Calcific band keratopathy after intraocular chondroitin sulfate. Arch Ophthalmol 1987; 105: 1243-1247.

42 Jensen OA. Ocular calcifications in primary hyperparathyroidism. Histochemical and ultrastructural study of a case. Comparison with ocular calcifications in idiopathic hypercalcemia of infancy and in renal failure. Acta Ophthalmol 1975; 53: 173-186.

43 Liesegang TJ. Viscoelastics. Int Ophthalmol Clin 1993; 33 $127-147$

44 Gasset AR, Lobo L, Houde W. Permanent wear of soft contact lenses in aphakic eyes. Am J Ophthalmol 1977; 83: $115-120$.

45 Winder AF, Ruben M, Sheraidah Ga. Tear calcium levels and contact lens wear. Br J Ophthalmol 1977; 61: 539-543.

46 Levy B. Calcium deposits on glyceryl methyl methacrylate and hydroxyethyl methacrylate contact lenses. Am J Optomet Physiol Opt 1984; 61: 605-607.

47 Bowers RWJ, Tighe BJ. Studies in the ocular compatibility of hydrogels: a review of the clinical manifestations of spoilation. Biomaterials 1987; 8: 83-88.

48 Bowers RWJ, Tighe BJ. Studies of the ocular compatibility of hydrogels: white spot deposits: chemical composition and geological arrangement of components. Biomaterials 1987; 8: $172-176$.

49 Tripathi RC, Tripathi BJ, Silverman RA, Rao GN. Contact lens deposits and spoilage: identification and management. Int Ophthalmol Clin 1991; 3: 91-120.

50 Dhaliwal DK, Mamamlis N, Olson RJ, Crandall AS, Zimmerman $\mathrm{P}$, Alldredge OC et al. Visual significance of glistenings seen in the AcrySof intraocular lens. J Cataract Refract Surg 1996; 22: 452-457.

51 Omar O, Pirayesh A, Mamalis N, Olson RJ. In vitro analysis of AcrySof intraocular lens glistenings in AcryPak and Wagon Wheel Packaging. J Cataract Refract Surg 1998; 24: 107-113

52 Anderson C, Koch DD, Green G, Patel A, Van Noy S. Alcon AcrySof $^{\mathrm{TM}}$ acrylic intraocular lens. In: Martin RG, Gills JP, Sanders DR (eds). Foldable Intraocular Lenses. Slack: Thorofare, NJ, 1993, pp 161-177.

53 Milauskas AT. Silicone intraocular lens implant discoloration in humans (letter). Arch Ophthalmol 1991; 109: 913.

54 Watt RH. Discoloration of a silicone intraocular lens 6 weeks after surgery (letter). Arch Ophthalmol 1991; 109: 1494.

55 Koch DD, Heit Le. Discoloration of silicone intraocular lenses (letter). Arch Ophthalmol 1992; 110: 319-320. 